\title{
The role of awake video-assisted thoracoscopic surgery in spontaneous pneumothorax
}

\author{
Eugenio Pompeo, MD, Federico Tacconi, MD, Davide Mineo, MD, and Tommaso Claudio Mineo, MD
}

From the Thoracic Surgery Division, Tor Vergata University School of Medicine, Rome, Italy.

This study was carried out within the Research Fellowship Program Tecnologie e Terapie Avanzate in Chirurgia appointed by Tor Vergata University.

Received for publication Aug 30, 2006; revisions received Oct 25, 2006; accepted for publication Nov 1, 2006.

Address for reprints: Eugenio Pompeo, MD, Cattedra di Chirurgia Toracica, Università Tor Vergata, V.le. Oxford 81, 00133, Rome, Italy (E-mail: pompeo@med.uniroma2.it).

J Thorac Cardiovasc Surg 2007;133:786-90

$0022-5223 / \$ 32.00$

Copyright $\odot 2007$ by The American Association for Thoracic Surgery

doi:10.1016/j.jtcvs.2006.11.001
Objective: We assessed in a randomized study the feasibility and efficacy of awake video-assisted thoracoscopic bullectomy with pleural abrasion to treat spontaneous pneumothorax.

Methods: Between January 2001 and June 2005, a total of 43 patients with primary spontaneous pneumothorax were randomly assigned by computer to undergo videoassisted thoracoscopic bullectomy and pleural abrasion under sole thoracic epidural anesthesia or general anesthesia with single-lung ventilation (control group). Primary outcome measures included technical feasibility and patient satisfaction with anesthesia as scored into 4 grades (from 1, unsatisfactory, to 4 , excellent). Secondary outcome measures included global operating room time, assessment of thoracic pain by visual analog pain scale, number of nursing care calls, hospital stay, and recurrences within 12 months.

Results: In the awake group, technical feasibility was scored as excellent, good, and satisfactory in 8, 7, and 6 patients, respectively. Intergroup comparisons (awake versus control) showed that global operating room time (78.0 \pm 20.0 vs $105.0 \pm$ 15.0 minutes, $P<.0001)$, perioperative visual analog pain scale score $(2.0 \pm 3.0 \mathrm{vs}$ $3.5 \pm 2.0, P=.005)$, nursing care calls $(2.0 \pm 1$ vs $3.0 \pm 3.0, P=.017)$, hospital stay $(2.0 \pm 1.0$ days vs $3.0 \pm 1.0$ days, $P<.0001)$, and overall costs $(€ 2540 \pm € 352$ vs $€ 3550 \pm € 435, P<.0001)$ were significantly better in the awake group. In the awake group, 5 patients $(23.8 \%)$ could be discharged within the first 24 postoperative hours. One patient in the awake group and 2 patients in the control group had recurrences within 12 months (difference not significant).

Conclusion: In our study, awake video-assisted thoracoscopic bullectomy with pleural abrasion proved easily feasible and resulted in shorter hospital stays and reduced procedure-related costs while providing equivalent outcome to procedures performed under general anesthesia.

$\mathrm{S}$ pontaneous pneumothorax (SP) is a relatively common condition, most often occurring in young, tall, thin adults. Management of SP includes simple pleural drainage and video-assisted thoracic surgery (VATS) bullectomy with or without pleurodesis, which can be performed by different methods. Although pleural drainage is often advocated as initial treatment, reserving surgery for recurrent SP, immediate surgical treatment has gained acceptance with the advent of VATS, which is routinely performed under general anesthesia with single-lung ventilation.

Having started a program of awake VATS under sole thoracic epidural anesthesia (TEA), ${ }^{1,2}$ we hypothesized that awake VATS bullectomy with pleural abrasion might be feasible and could result in better procedure acceptance, more rapid recovery, and reduced procedure-related costs because of the avoidance of general anesthesia-related adverse effects and discomfort. ${ }^{3,4}$ 


\section{Abbreviations and Acronyms \\ ELC = emphysemalike changes \\ SP $=$ spontaneous pneumothorax \\ TEA $=$ sole thoracic epidural anesthesia \\ VAS = visual analog pain scale \\ VATS $=$ video-assisted thoracic surgery}

We therefore compared in a randomized study the results of awake VATS bullectomy with pleural abrasion with those of the same procedure performed under general anesthesia with single-lung ventilation.

\section{Patients and Methods}

The study started in January 2001 and was closed in June 2005. It was approved by the ethical committee of the Tor Vergata University, and all recruited patients gave their written informed consent once the investigational nature of the study and characteristics of each surgical approach had been explained. All patients were referred to our institution under an urgency-based regimen. To be eligible, patients required a primary SP larger than $15 \%$ on admission chest radiograph without concomitant pulmonary disease other than emphysemalike changes (ELCs) on high-resolution computed tomography (Table 1).

Primary outcome measures included technical feasibility and patient satisfaction with anesthesia, scored into 4 grades (4, excellent; 3 , good; 2, satisfactory; 1 , unsatisfactory). Secondary outcome measures were anesthesia time (defined as the time required to perform anesthesia) operative time (defined as the time between skin incision and completion of skin closure), global operating room time (defined as the sum of anesthesia time, operative time, weaning time, and time required in the recovery room to achieve a stable clinical condition necessary for transfer to the ward), nursing care need (scored by recording the number of patient calls for nursing care during the first 24 postoperative hours), recurrences within 12 months, and hospital stay. In addition, the ratio of $\mathrm{PaO}_{2}$ to fraction of inspired oxygen and the $\mathrm{PaCO}_{2}$ were assessed intraoperatively, at the completion of the surgical procedure, and 24 hours after surgery. Postoperative pain was assessed by a standard visual analog pain scale (VAS).

Criteria for chest tube removal and discharge were standardized and included complete lung re-expansion demonstrated on chest radiography, pleural drainage less than $150 \mathrm{~mL} / \mathrm{d}$, and no air leak for 12 hours. No patient was discharged with a Heimlich valve.

\section{Cost Analysis}

Procedure-related costs included devices (epidural catheter, bilumen tracheal tube, liquid infusions, anesthetic drugs, and staplers and other surgical instrumentation), analgesic drugs, antibiotics, routine laboratory assessment, dressing materials, operating timerelated costs and hospital stay. Device costs are those available at the Policlinico Tor Vergata Internal Service by agreement with the manufacturers. Global operating room costs are estimated from operating room cost per hour.

\section{TABLE 1. Entry criteria}

Diagnosis of primary spontaneous pneumothorax with no
underlying lung disease other than emphysemalike
changes on high-resolution computed tomography
Pneumothorax $>15 \%$ on admission chest radiograph
-
No comorbidity
- $\quad$ No previous thoracic surgery on the involved side
-
Acceptance of surgical treatment
Acceptance of random assignment
No contraindication for thoracic epidural anesthesia
-

\section{Anesthesia}

The objective of TEA was to achieve somatosensory and motor block at the TI-T8 levels while preserving diaphragmatic respiration. After premedication with intravenous midazolam, the thoracic epidural catheter was inserted in the operating room at the $\mathrm{T} 4$ level, and continuous infusion of $0.5 \%$ ropivacaine (INN) was started.

Whenever somatosensory block was judged unsatisfactory by the patient, additional anesthesia was provided by local injection of a $50 \%$ mixture of $7.5 \%$ ropivacaine and $2 \%$ bupivacaine hydrochloride (INN bupivacaine), with attention to infiltrating the intercostal space in an extrapleural plane under thoracoscopic view. During wound closure, the TEA anesthetic regimen was changed to $0.2 \%$ ropivacaine and $1-\mu \mathrm{g} / \mathrm{mL}$ sufentanil at an administration rate of 2 to $5 \mathrm{~mL} / \mathrm{h}$ to provide optimal postoperative analgesia. At the end of the procedure, intravenous fluid infusions were interrupted, and the patient was immediately encouraged to drink and walk. The epidural catheter was removed within the first 48 hours.

In patients undergoing nonawake procedures, general anesthesia was induced with intravenous propofol $(1.5-2 \mathrm{mg} / \mathrm{kg})$, fentanyl $(0.1$ $\mathrm{mg})$, and vecuronium bromide $(0.1 \mathrm{mg} / \mathrm{kg})$. A left-sided doublelumen tube was used. Postoperative analgesia was performed with continuous infusion of tramadol and ketorolac tromethamine (INN ketorolac) through an elastomeric device.

\section{Surgical Technique}

Identical surgical techniques and patient positions were used in the study groups. The patient was placed in full lateral decubitus position. A first trocar port was inserted in the 7 th intercostal space, in the midaxillary line. Two additional trocars were placed in the 5th and 4th intercostal spaces in the anterior and posterior axillary lines, respectively. Careful exploration of the lung was accomplished to discover ELCs. Bullectomy was performed with an EndoPath 45 mechanical stapler with 3.5-mm cartridges (Ethicon Endo-Surgery SpA, Pomezia, Italy). If no ELCs were identified, lung apicectomy was carried out in the same manner. Pleural abrasion was performed with a dedicated mesh abrader. At the completion of the procedure, a 28F chest drainage was inserted through the camera port incision and placed on suction $\left(-20 \mathrm{~cm} \mathrm{H}_{2} \mathrm{O}\right)$.

\section{Statistical Methods}

In a historical cohort undergoing VATS bullectomy plus pleural abrasion at our institution, $15 \%$ of the patients were discharged 
TABLE 2. Demographic and preoperative data

\begin{tabular}{lccc}
\hline & $\begin{array}{c}\text { Awake } \\
\text { group }\end{array}$ & $\begin{array}{c}\text { Control } \\
\text { group }\end{array}$ & $\begin{array}{c}\boldsymbol{P} \\
\text { value }\end{array}$ \\
\hline Age (y, median \pm quartile range) & $28 \pm 14$ & $26 \pm 11$ & .76 \\
Male/female ratio & $17: 4$ & $17: 5$ & .76 \\
Smoking exposure & $16(76 \%)$ & $17(77 \%)$ & .93 \\
Inhaled drugs abuse & $2(9.5 \%)$ & $3(14 \%)$ & .67 \\
Right/left ratio & $11: 10$ & $11: 11$ & .87 \\
ELCs on high-resolution computed & $12(57 \%)$ & $14(64 \%)$ & .66 \\
$\quad$ tomography & $19(90 \%)$ & $21(95 \%)$ & .52 \\
ELCs at video-assisted & & & \\
$\quad$ thoracoscopic surgery & $18(86 \%)$ & $19(86 \%)$ & .96 \\
Initial pleural drainage & $3(14 \%)$ & $1(4 \%)$ & .22 \\
Pleural adhesions & & & \\
\hline
\end{tabular}

Values are reported as absolute numbers of patients with percentages except as otherwise noted. Differences analyzed by Mann-Whitney test. ELCs, Emphysemalike changes.

within the first 48 hours, so trial size was originally determined by the number of patients necessary to yield (by a nonparametric 2-sided test with an $\alpha$ error of .05) an increment of at least $10 \%$ of discharges within the same time. Group descriptive statistics are presented as median \pm quartile range. The nonparametric Mann-Whitney U test was used for comparison of unpaired data. Frequencies were compared with a 2-tailed Fisher exact test. Correlations were tested with the Spearman correlation coefficient.

\section{Results}

Demographics

Out of 49 patients who met the entry criteria during the study-period, 6 patients $(12.2 \%)$ refused randomization and preferred a nonawake procedure. As a result, 21 patients were assigned by computer to the awake group and 22 patients to the control group. Fifteen patients had first instance SP, 19 patients had had one previous episode, and other 9 patients had had two or more episodes on the same side. Thirty-three patients were current or former smokers. Five patients reported a history of inhaled drug abuse. The study groups were well matched in term of baseline measures and preoperative data (Table 2).

\section{Operative Results}

Between-groups comparisons of operative findings are detailed in Table 3. There was no difference in operating time, whereas anesthesia time, recovery room time, and global operating room time were all significantly shorter in the awake group, mainly because of the lack of weaning time.

In the awake group, technical feasibility was scored as excellent, good, and satisfactory in $8(38.0 \%), 7$ (33.3\%), and $6(28.6 \%)$ patients, respectively, with no intergroup difference. A merely satisfactory feasibility score in the awake group was due to coughing during lung manipulation in 3 patients, thoracic pain requiring additional local anesthesia at the trocars sites in 2 patients, and tachypnea from permissive hypercapnia in 1 patient.

No patient had respiratory or cardiac impairment throughout the awake procedure, and the only adverse intraoperative event was panic attack, which occurred in 2 patients and was controlled with additional boluses of midazolam. No patient in this group required conversion to general anesthesia.

Intraoperative $\mathrm{PaCO}_{2}$ peak was higher in the awake group, whereas 24 hours after the procedure, $\mathrm{PaCO}_{2}$ was

TABLE 3. Operative results

\begin{tabular}{|c|c|c|c|c|c|}
\hline & \multicolumn{2}{|c|}{ Awake group } & \multicolumn{2}{|c|}{ Control group } & \multirow[b]{2}{*}{$P$ value } \\
\hline & Median $\pm \mathbf{O R}$ & $95 \% \mathrm{Cl}$ & Median $\pm \mathbf{O R}$ & $95 \% \mathrm{Cl}$ & \\
\hline Anesthesia time (min) & $25.0 \pm 6.0$ & $23.9-28.8$ & $35.5 \pm 10.0$ & $33.7-39.6$ & $<.0001$ \\
\hline Recovery room time (min) & $20.0 \pm 15.0$ & $16.1-24.8$ & $30.0 \pm 15.0$ & $26.9-36-6$ & .001 \\
\hline Operative time (min) & $32.0 \pm 15.0$ & $28.2-36.7$ & $35.0 \pm 15.0$ & $29.0-35.8$ & .84 \\
\hline Global operating room time (min) & $78.0 \pm 20.0$ & 73.8-84.7 & $105.0 \pm 15.0$ & $95.2-107.3$ & $<.0001$ \\
\hline Hospital stay (d) & $2.0 \pm 1.0$ & $1.8-2.6$ & $3.0 \pm 1.0$ & $3.1-4.2$ & $<.0001$ \\
\hline Technical feasibility score & $3.0 \pm 2.0$ & $2.7-3.4$ & $4.0 \pm 1.0$ & $3.2-3.8$ & .06 \\
\hline Anesthesia satisfaction score & $4.0 \pm 1.0$ & $2.9-3.7$ & $3.0 \pm 1.0$ & $2.3-3.1$ & .02 \\
\hline VAS score, end operation & $2.0 \pm 3.0$ & $1.2-2.5$ & $3.5 \pm 2.0$ & $2.5-3.7$ & .005 \\
\hline VAS score, peak & $5.0 \pm 3.0$ & $3.8-5.4$ & $5.0 \pm 3.0$ & $4.0-5.2$ & .89 \\
\hline Intraoperative $\mathrm{PacO}_{2}(\mathrm{~mm} \mathrm{Hg})$ & $45.0 \pm 5.0$ & $42.7-46.9$ & $40.0 \pm 5.0$ & $38.5-42.0$ & .002 \\
\hline 12-h $\mathrm{PaCO}_{2}(\mathrm{~mm} \mathrm{Hg})$ & $42.0 \pm 7.0$ & $39.4-43.1$ & $46.0 \pm 8.0$ & $41.8-47.0$ & .046 \\
\hline Intraoperative $\mathrm{PaO}_{2} / \mathrm{FiO}_{2}$ ratio & $3.7 \pm 0.5$ & $3.5-4.0$ & $3.7 \pm 0.5$ & $3.5-3.8$ & .63 \\
\hline 12-h $\mathrm{PaO}_{2} / \mathrm{FiO}_{2}$ ratio & $3.8 \pm 0.4$ & $3.6-4.0$ & $3.8 \pm 0.3$ & $3.6-3.9$ & .68 \\
\hline Nursing care need (No. of calls) & $2.0 \pm 1.0$ & $1.8-2.7$ & $3.0 \pm 3.0$ & $2.6-3.8$ & .017 \\
\hline Global cost $(€)^{*}$ & $2540 \pm 352$ & & $3550 \pm 435$ & & $<.0001$ \\
\hline
\end{tabular}

$Q R$, Quartile range; $C l$, confidence interval; $V A S$, visual analog pain scale; $\mathrm{FiO}_{2}$, fraction of inspired oxygen. *Costs are reported as mean $\pm \mathrm{SD}$. 
slightly higher in the control group. No patient in either group had severe hypercarbia or acid-base imbalance.

In the immediate postoperative period, perioperative pain was significantly lower in the awake group, whereas no between-group difference was found in peak VAS score. A significantly higher number of nursing care calls occurred in the nonawake group and correlated with end-operation VAS score (Spearman $r 0.42, P=.04$ ). Patient satisfaction score for anesthesia was significantly better in the awake arm.

Overall, there was no mortality or major morbidity. In the awake arm, minor complications included vomiting and transitory urinary retention in 1 patient each. Persistent air leaks ( $>3$ days) occurred in 2 patients in the nonawake group and in 1 patient in the awake group.

The median hospital stay was significantly shorter in the awake group. In particular, for the awake versus control group comparison, 8 patients in the awake group (38.1\%) were discharged within 48 hours, versus $5(22.7 \%)$ in the control group $(P=.33)$. In the awake group, 5 patients $(23.8 \%)$ were discharged within 24 hours, versus none in the control group $(P=.02)$. The reduced hospitalization in the awake group translated into lower procedure-related costs $(P<.0001)$. No patients were unavailable for followup, and recurrences within 12 months were comparable between the study groups (1 vs 2 ).

\section{Discussion}

Awake VATS represents a particularly attractive approach for treatment of SP because of the simplicity of the surgical procedure and the peculiar characteristics of the young patient population. In fact, patients with primary SP have an optimal cardiopulmonary status, which is less likely to be impaired throughout an awake VATS procedure. Furthermore, diffuse pleural adhesions, which can be contraindications for awake VATS, are exceedingly rare in these patients. ${ }^{5}$

In previous studies we have shown that awake resection of pulmonary nodules ${ }^{1}$ and lung volume-reduction surgery ${ }^{2}$ are feasible and safe.

The most noteworthy finding of our study is that awake VATS bullectomy with pleural abrasion is feasible and well tolerated, although it must be noted that $12 \%$ of recruitable patients refused random assignment and preferred a nonawake procedure. Among primary outcomes, technical feasibility was similar between the study groups. This could be because during awake VATS the open pneumothorax induced by inserting the thoracoports is followed by a nearly complete lung collapse almost equivalent to that achieved through single-lung ventilation. In some instances, we have found technical feasibility to be somewhat less than ideal because of disturbing features, which have included coughing reflexes during lung manipulation, hyperventilation induced by permissive hypercapnia, and unexpected thoracic pain requiring additional local anesthesia. Global operating room time and hospital stay were shorter in the awake group, however, and hospital charges were also lower than those of the control group.

Awake surgery for SP is not new. In 1997, Nezu and coworkers ${ }^{6}$ already reported satisfactory results with awake VATS bullectomy with sole intercostal blockade, and use of TEA has been anecdotally investigated in this setting. ${ }^{7,8} \mathrm{We}$ believe that the use of TEA is particularly appealing when VATS bullectomy with pleural abrasion is elected, because an optimal somatosensory block is advisable to minimize thoracic pain. Furthermore, because TEA obviates the need for deep sedation, interactive cooperation between the surgeon and the conscious patient is possible. In particular, the surgeon can invite the patient to breathe either more slowly when $\mathrm{PaCO}_{2}$ tends to increase or more deeply when lung re-expansion is needed.

The ideal technique to be added as a completion to bullectomy to reduce risk of recurrence in patients with SP is still matter of debate. We support pleural abrasion as a reliable method of mechanical pleurodesis, as suggested by the optimal patient tolerability and the satisfactory recurrence rate. ${ }^{9}$ Talc pleurodesis has been advocated by others authors because of its effectiveness and easy feasibility. ${ }^{10}$ Severe complications, however, including acute respiratory distress syndrome, have been described in the literature with the use of talc, which also proved less effective in presence of bullae larger than $2 \mathrm{~cm} .{ }^{11}$ Moreover, we observed foreign-body reactions evolving into inflammatory pseudotumors in 2 patients who had previously undergone talc pleurodesis for pneumothorax at other institutions, a finding that reinforces our preference to avoid talc pleurodesis in young, healthy patients with SP.

Five patients in our series had a history of drug abuse. This could play a role not only in initial development of SP but also in recurrence after surgery.

Such findings support the hypothesis that outcome may be affected by factors other than the surgical procedure or the learning curve, ${ }^{12}$ including patient behavior and even the quality of postoperative medical management. In this respect, Lardinois and coworkers ${ }^{13}$ have recently reported that nonsteroidal analgesic drugs can significantly alter the quality of pleurodesis in pigs treated with pleural abrasion.

Data from the literature show that the prevalence of ELCs in patients treated with VATS for SP ranges from $76 \%$ to $100 \%$. $^{5,14}$ Because missed detection of ELCs is thought to be an independent predictor of recurrence, ${ }^{14}$ the question of whether awake VATS can yield optimal recognition of ELCs seems crucial. In our series, blebs or bullae were found in most patients, with no between-group differences. These findings are in agreement with those by Nezu and coworkers ${ }^{6}$ and suggest that awake VATS did not jeopardize a careful exploration of the entire lung surface, thus allowing easy identification of ELCs without the need 
for carbon dioxide insufflation. Moreover, awake VATS facilitated detection of blebs and bullae, which remained insufflated during spontaneous breathing because of their high compliance, without the need for mechanical ventilation of the collapsed lung, which may cause lung injury. ${ }^{4}$

With respect to the debate on whether patients with first occurrence SP should undergo surgery, ${ }^{14,15}$ we acknowledge that multiple factors contribute to the decision-making process in this setting, including the patient's preference, the surgeon's habitual practice, and the clinical scenario. In our opinion, the $20 \%$ to $60 \%$ recurrence rate ${ }^{14}$ observed after conservative treatment compares unfavorably with that reported after immediate surgery. ${ }^{14,16,17}$ Although further investigation is needed, cost analysis showed a reduction in overall hospital charges in the awake arm, a finding that supports immediate surgical treatment for these patients.

The finding of a correlation between early postoperative thoracic pain and need for nursing care in nonawake patients led us to hypothesize that the degree of postoperative discomfort might be conditioned more importantly by the initial pain's perception after weaning. Awake procedures thus might accelerate recovery as a result of a lesser impairment of cortical functions in the early postanesthesia phase.

\section{Limitations}

The foremost limitation of our study is its entry criteria. In fact, it is conceivable that awake VATS might be applicable in elderly patients with secondary pneumothorax, or in those with high surgical risk. In our study, however, we decided initially to assess feasibility and outcome of a simple surgical procedure performed in a healthy population. This was done to reduce operative risk and the influence of confounding, interacting variables.

We acknowledge as another limitation the recurrence rate estimation, which embraces a relatively short period and could lead to missed late recurrences. We arbitrarily chose this limit to avoid the influence of the disease natural history on late outcome. Furthermore, there is evidence in the literature that most recurrences appear within the first 12 months. ${ }^{14,17,18}$ Finally, the use of different methods for thoracic analgesia in the study groups (ie, epidural catheter and peripheral elastomeric device) might also be criticized, although the idea to use epidural plus general anesthesia and double lumen-tube intubation in the control group was considered during the trial setup but subsequently abandoned because of the limited physiologic impact of the surgical procedure.

\section{Conclusions}

Our randomized study has shown that awake VATS bullectomy with pleural abrasion is feasible and results in shorter hospital stay and reduced procedure-related costs relative to procedures performed with general anesthesia, with singlelung ventilation and equivalent 12-month outcome than legendary. Further investigation with longer follow-up is welcome to refine, contradict, or corroborate our findings.

\section{References}

1. Pompeo E, Mineo D, Rogliani P, Sabato AF, Mineo TC. Feasibility and results of awake thoracoscopic resection of solitary pulmonary nodules. Ann Thorac Surg. 2004;78:1761-8.

2. Mineo TC, Pompeo E, Mineo D, Tacconi F, Marino M, Sabato AF. Awake nonresectional lung volume reduction surgery. Ann Surg. 2006; 243:131-6

3. Fossard JP, Samet A, Meilstelman C, Longrois D. Life-threatening pneumothorax of the ventilated lung during thoracoscopic pleurectomy. Can J Anaesth. 2001;48:493-6.

4. Whitehead T, Slutsky AS. The pulmonary physician in critical care. 7 : Ventilator induced lung injury. Thorax. 2002;57:635-42.

5. Janssen JP, Schramel FM, Sutedja TG, Cuesta MA, Oosterhuis W, Postmus PE. Videothoracoscopic appearance of first and recurrent pneumothorax. Chest. 1995;108:330-4.

6. Nezu K, Kushibe K, Tojo T, Takahama M, Kitamura S. Thoracoscopic wedge resection of blebs under local anesthesia with sedation for treatment of a spontaneous pneumothorax. Chest. 1997;111:230-5.

7. Sugimoto S, Date H, Sugimoto R, Okazaki M, Aoe M, Sano Y, et al. Thoracoscopic operation with local and epidural anesthesia in the treatment of pneumothorax after lung transplantation. J Thorac Cardiovasc Surg. 2005;130:1219-20.

8. Yokoyama T, Tomoda M, Kanbara T, Nishiyama T, Manabe M Epidural anesthesia for a patient with catamenial pneumothorax. Masui. 2001;50:290-2.

9. Mouroux J, Elkaim D, Padovani B, Myx A, Perrin C, Rotomondo C, et al. Video-assisted thoracoscopic treatment of spontaneous pneumothorax: technique and results of one hundred cases. J Thorac Cardiovasc Surg. 1996;112:385-91.

10. Tschopp JM, Boutin C, Astoul P, Janssen JP, Grandin S, Bolliger CT, et al. Talcage by medical thoracoscopy for primary spontaneous pneumothorax is more cost-effective than drainage: a randomised study. Eur Respir J. 2002;20:1003-9.

11. Tschopp JM, Brutsche M, Frey JG. Treatment of complicated spontaneous pneumothorax by simple talc pleurodesis under thoracoscopy and local anesthesia. Thorax. 1997;52:329-32.

12. Ohno K, Miyoshi S, Minami M, Akashi A, Maeda H, Nakagawa K, et al. Ipsilateral recurrence frequency after video-assisted thoracoscopic surgery for primary spontaneous pneumothorax. Jpn J Cardiovasc Surg. 2000;48:757-60.

13. Lardinois D, Vogt P, Yang L, Hegyi I, Baslam M, Weder W. Nonsteroidal anti-inflammatory drugs decrease the quality of pleurodesis after mechanical pleural abrasion. Eur J Cardiothorac Surg. 2004;25 865-71.

14. Schramel FM, Postmus PE, Vanderschueren RG. Current aspects of spontaneous pneumothorax. Eur Respir J. 1997;10:1372-9.

15. Schramel FM, Sutedja JC, Braber JC, Van Mourik JC, Postmus PE. Cost-effectiveness of video assisted thoracoscopic surgery versus conservative treatment for first time or recurrent spontaneous pneumothorax. Eur Respir J. 1996;9:1821-5.

16. Lang-Lazdusnski L, Chapuis O, Bonnet PM, Pons F, Jancovici R. Videothoracoscopic bleb excision and pleural abrasion for the treatment of primary spontaneous pneumothorax: long-term results. Ann Thorac Surg. 2003;75:960-5.

17. Inderbitzi RG, Leiser A, Furrer M, Althaus U. Three years' experience in video-assisted thoracic surgery (VATS) for spontaneous pneumothorax. J Thorac Cardiovasc Surg. 1994;107:1410-5.

18. Yim AP, Ho JK, Lai CK, Chan HS. Primary spontaneous pneumothorax treated by video assisted thoracoscopic surgery-results of intermediate follow up. Aust N Z J Med. 1995;25:146-50. 